\title{
Real Estate Development Strategy Based on Artificial Intelligence and Big Data Industrial Policy Background
}

\author{
Yu Liu ii \\ School of Management, Harbin Institute of Technology, Harbin, Heilongjiang 150006, China \\ Correspondence should be addressed to Yu Liu; liuyu_vip@outlook.com
}

Received 14 December 2021; Accepted 20 January 2022; Published 2 March 2022

Academic Editor: Punit Gupta

Copyright (c) $2022 \mathrm{Yu}$ Liu. This is an open access article distributed under the Creative Commons Attribution License, which permits unrestricted use, distribution, and reproduction in any medium, provided the original work is properly cited.

\begin{abstract}
In recent years, as one of the pillar industries of the national economy, the real estate industry has achieved unprecedented development. Since the 1990s, my country's real estate industry has experienced three decades of rapid development. The average annual growth of commercial housing area is nearly $20 \%$, and the average annual growth of housing prices in second-tier cities is $11.87 \%$. However, in the rapid development, there are also many problems. For example, there are more and more phenomena such as unreasonable development, serious environmental pollution, and shortage of resources. At the same time, artificial intelligence has made great achievements in the development process in recent years, and it has continued to grow with technological progress and social demand. At present, China is in a transitional period of economic and social development, and the real estate industry is also facing huge challenges. In this context, research and development of traditional Chinese cities is very necessary and important. Therefore, how to effectively control and coordinate the real estate development behavior in the big data environment is one of the major problems that China is facing and needs to be solved urgently. This article uses questionnaire surveys and data analysis methods to understand the elements of real estate development strategies and analyze consumer purchase intentions through questionnaires. Randomly select 120 citizens of $\mathrm{P}$ city as the survey objects, and carry out a questionnaire survey. According to the survey results, most of the interviewees believe that the resource integration strategy occupies an important position in the real estate development strategy, and the big data management strategy also exerts its advantages. Most people believe that internal demand motivation is the most important, followed by the characteristics of real estate. It can be seen that real estate development must fully consider the actual needs of consumers and improve the development process to highlight the characteristics of real estate.
\end{abstract}

\section{Introduction}

The rapid development of artificial intelligence technology has brought earth-shaking changes to human life. As a new real estate development model under the background of the big data industry policy, smart real estate projects have become a current research hotspot at home and abroad. Under such circumstances, China has begun to vigorously promote smart housing, smart cities, and green buildings. How to effectively control and coordinate the real estate development behavior in the big data environment is one of the major problems that China is facing and needs to be solved urgently. Therefore, in the context of artificial intelligence and big data industrial policies, it is very necessary to carry out relevant research on real estate development strategies.

At present, the research results on the application of artificial intelligence and big data to real estate development are relatively rich. For example, Shi pointed out that China has been committed to the research and development of artificial intelligence, and the rapid rise and continuous development of big data technology have been widely used in various fields [1]. Luo analyzed the combination of big data technology and management accounting work, discussed the main points of management accounting work after the application of big data technology in real estate enterprises, and provided useful references and learning lessons for the same industry [2]. Jin and Li believed 
mastering residential property development and management strategies, developing commercial properties, maximizing the benefits of commercial property development and construction, and grasping the correct direction of commercial real estate development, so as to promote the development of urban commercial real estate [3]. Therefore, this article combines artificial intelligence and big data industrial policies to conduct research on real estate development strategies.

This research is based on the questionnaire survey method; through data analysis and arrangement, it draws suggestions for the development of the real estate market. This article mainly discusses these aspects. First of all, it elaborates on artificial intelligence and its related content. Then, it also introduces the big data industry and its policies and carries out related research. In addition, it discusses real estate development and strategies. Finally, a questionnaire survey is launched, and relevant survey results and analysis conclusions are drawn. The development of the research will not only help alleviate the troubled situation of my country's real estate development and promote the sustainable development of the industry but also help to better promote the integration of the real estate industry with information technology and fill the gaps in related research.

\section{Related Theoretical Overview and Research}

2.1. Artificial Intelligence. The research of artificial intelligence is to explore and imitate the intelligence that exists in the natural world and apply it to real life. And artificial intelligence can also be called an automated, programmed machine. Artificial intelligence is a subject, and its research fields mainly include biotechnology, computer simulation, and industrial automation. For example, people use artificial intelligence to perform speech recognition, breaking through the barriers to sound signal reception. In medicine, machines can also be used instead of people to perform some pathological or other disease diagnosis works $[4,5]$.

The development of artificial intelligence has gone through three stages. In the first stage, computer technology and sensor technology are combined to form an intelligent system. One is to simply complete tasks, and the other is to automatically process and detect information. In the second stage, the combination of "big data" technology and AI has formed a new model that provides conditions for humancomputer interaction. The third stage is the transition from the researchers beginning in the direction of robot learning to the real realization of automated production processes, such as intelligent equipment and robots.

Artificial intelligence is an emerging technology, which has the following basic characteristics. One is intelligence. The robot runs and controls the computer system. The second is simple operation. It can change its own functions and performance according to changes in external conditions, and at the same time, it can self-learn and improve artificial intelligence through programs to make it continuously adapt to the external environment $[6,7]$.
2.2. Big Data Industry Policy and Related Research. With the advent of the Internet era and the continuous emergence of new technological revolutions such as cloud computing and information science, it has had a profound impact on social and economic development, and at the same time, it has provided more convenient services to humans in life. The big data industry is an emerging research field, which is based on cloud computing, the Internet of Things, and mobile internet, and relies on information processing technology.

Big data is not only innovation and technological progress but also has greatly changed the path of social development. At the same time, big data has become a weapon to lead the global economic and social transformation and promote the modernization of traditional industries. However, this is precisely because they belong to emerging industries, and their development trends are more difficult to grasp. Therefore, countries all over the world are actively adopting new big data strategies, actively promoting the development of the big data industry, and grasping the development trend [8,9]. Table 1 shows the development index of China regional big data industry.

The big data industry is inseparable from the support of big data. Big data has become an important driving force and is developing into an emerging industry dominated by technology and information services. Therefore, data and big data technologies provide prerequisites for the emergence of the big data industry, and the application of big data drives the development of the big data industry.

Behind the vigorous development of the big data industry, there are also many hidden dangers such as talent and technology, weak industrial foundation, insufficient innovation and application, and imperfect laws and regulations. The existence of these problems severely restricts the future development of China's big data industry. Nowadays, more and more countries realize the importance of the big data industry and implement industrial policies one after another.

The big data industrial policy is an organic whole, which organically integrates various specific industrial policies, in which various components cooperate and interconnect with each other. After the development of the big data industry has gone through the initial exploration and start-up stages, the development of the big data industry has moved from the understanding of the theoretical basis to the industrial construction, promotion, and acceptance of big data technology and applications. With the gradual maturity of the society, the entire industry has developed rapidly, and the scope of the industry has gradually expanded $[10,11]$.

The big data industry policy has played an effective role in promoting the development of the big data industry. It can be summarized into four aspects, namely, the technology policy, structural policy, layout policy, and organizational policy of the big data industry. The big data industry is an important driving force for future social and economic development, and the structural policy of the 
TABle 1: Big data industry development index by region.

\begin{tabular}{lcccc}
\hline Development index & Eastern area & Western area & Middle area & Northeastern area \\
\hline 2017 & 471.324 & 346.533 & 186.714 & 83.612 \\
2018 & 510.241 & 386.412 & 230.772 & 100.231 \\
2019 & 590.783 & 457.561 & 298.134 & 178.424 \\
\hline
\end{tabular}

big data industry is also an important part of the big data industry policy.

In response to the development of China's big data industry, the introduction of big data industry layout policies can promote the integration and concentration of data resources. The inequality in the development of big data industries in different regions and different industries can help promote each region. Each region also adopts different big data industry layout guidelines based on its own regional advantages and the status quo of the big data industry. Optimizing the big data industry organization policy is one of the important tasks to promote the development of China big data industry. It can better regulate the relationship between enterprises, maintain normal market order, and promote effective competition $[12,13]$. Figure 1 shows the relationship between the main elements of the big data industry and the big data industry policy.

2.3. Real Estate Development and Strategic Research. Although there have been several bubbles during the development of the real estate industry, the real development of the real estate industry was after the abolition of the subsystem.

Real estate development is a comprehensive project that involves a wide range of areas, requires consideration of many factors, and is affected by multiple conditions throughout the process. Therefore, real estate projects have obvious particularities. From the preliminary investigation, planning, design, and construction of the project to the completion and acceptance, they are closely related to the land.

If real estate wants to develop and operate better, it is necessary to avoid the impact of residential real estate as much as possible and to find a fit for a commercial real estate development model with Chinese characteristics in accordance with the law of real estate development. Therefore, if commercial real estate wants to develop better, it needs to clarify the relevant theoretical basis first, and at the same time, it is necessary to learn a lot of advantages of Western developed countries in the commercial real estate development and operation process for reference. Solve various problems encountered in the development of China commercial real estate, and provide reference for the development of commercial real estate $[14,15]$.

There are three main branches of real estate development theory. The first is the theory of market analysis, which analyses and compares consumer needs, buying behavior, and sales methods with real estate companies as the research object and grasps the product life cycle through changes in the consumption environment and conditions. The second is the economic income hypothesis, which mainly includes two parts, population growth and per capita disposable income, as well as new benefits brought about by technological progress. The third is the theory of social structure, which refers to various production factors formed in the history of human society.

Real estate development strategy usually refers to the methods or means adopted by an enterprise in order to gain a competitive advantage and create greater and more profits within a certain range. From an economic perspective, strategic management theories can be divided into three types. The first is the combination strategy, the second is the overall policy, and the third is the external environment strategy. Real estate development projects generally have the characteristics of large scale and wide distribution. Therefore, reasonable planning and design of corresponding engineering schemes are required to improve their economic benefits and social impact effects. This is also one of the important goals implemented by developers [16, 17].

In addition, companies must fully investigate the current status of real estate development before formulating development strategies. Choose the right project and operating model not only to reduce the debt ratio and solve the problem of tight cash flow but also to obtain sales revenue in the shortest possible time.

The entire operation process of real estate is complex, including land development in the early stage and sales and promotion in the middle and later stages. Only by ensuring the smooth completion of each link can the entire project run smoothly. The real estate development process is shown in Figure 2.

\section{Questionnaire and Research}

3.1. Questionnaire Design Process. The questionnaire survey selected the citizens of city $\mathrm{P}$, including consumers, real estate developers, and real estate sales staff. Through the issuance of online questionnaires or paper questionnaires, the collection and quantitative analysis of the information filled in by users are carried out to draw conclusions of the questionnaire.

(1) In the preliminary preparation of the questionnaire, the number of questions should be as concise as possible to avoid fatigue of the interviewees.

(2) The questionnaire is released. Questionnaires were distributed through online questionnaires, on-site questionnaires, and inviting friends to help ask friends and students around them. A total of 140 


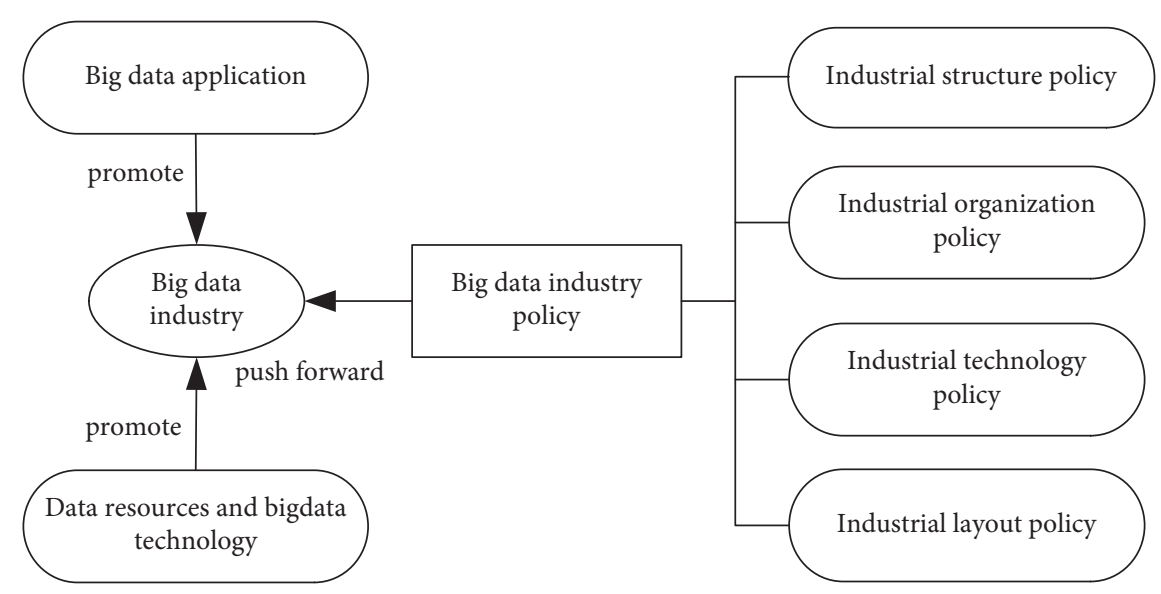

FIGURE 1: Relationship between the main elements of the big data industry and the policy.

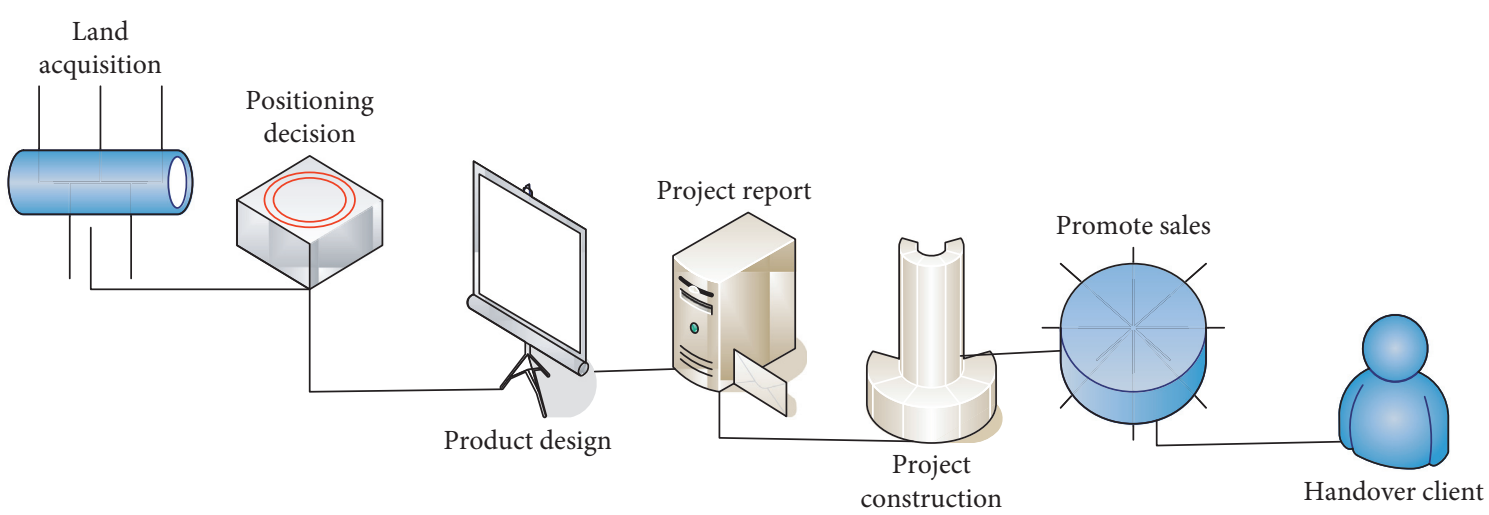

FIgURE 2: Real estate development process.

questionnaires were distributed, 120 valid questionnaires were returned, and the questionnaire recovery rate was $85.71 \%$. The questionnaire distribution method and the results of the collection are shown in Table 2.

(3) Questionnaire analysis: organize the collected questionnaire information to get the required information data. Analyze the results of the questionnaire, including analysis of real estate development strategies and consumer purchase intentions. Some of the results obtained from the questionnaire are as follows.

3.2. Analysis of the Reliability and Validity of the Questionnaire. Reliability and validity testing is a very important link in the process of empirical research and is used to ensure the quality of questionnaires used in survey research $[18,19]$. Only when the measurement tool (i.e., questionnaire) meets the reliability and validity requirements, the research results can be convincing $[20,21]$. The specific calculation method is shown in formulas (1) and (2):

$$
\begin{aligned}
& \lambda_{d}=\frac{\left(\sum \theta\right)^{2}}{\left[\left(\sum \theta\right)^{2}+\sum(\theta)\right]^{2}}, \\
& \lambda_{e}=\frac{\left(\sum \theta^{2}\right)}{\left[\left(\sum \theta^{2}\right)+\sum(\sigma)\right]} .
\end{aligned}
$$

Among them, $\lambda_{d}$ is the combined reliability, $\lambda_{e}$ is the average extraction variance, $\theta$ is the standardized factor, and $\sigma$ is the measurement error variance of the observed variable $[22,23]$.

3.3. Questionnaire Survey Content. The first part is the selected 120 citizens of city P, including consumers, real estate developers, and real estate sales staff, to investigate real estate development strategies in terms of resource integration, consumer experience, e-commerce integration, and big data management [24, 25].

The second part is to sort out the information collected by the questionnaire and investigate and analyze consumers' purchase intentions in terms of personal characteristics, internal 
TABLE 2: Questionnaire distribution method and collection results.

\begin{tabular}{lccc}
\hline Questionnaire distribution method & Number of questionnaires issued & Number of questionnaires returned & Recovery rate (\%) \\
\hline Internet questionnaire & 45 & 41 & 91.1 \\
On-site questionnaire & 57 & 52 & 91.23 \\
E-mail & 38 & 27 & 71.05 \\
\hline
\end{tabular}

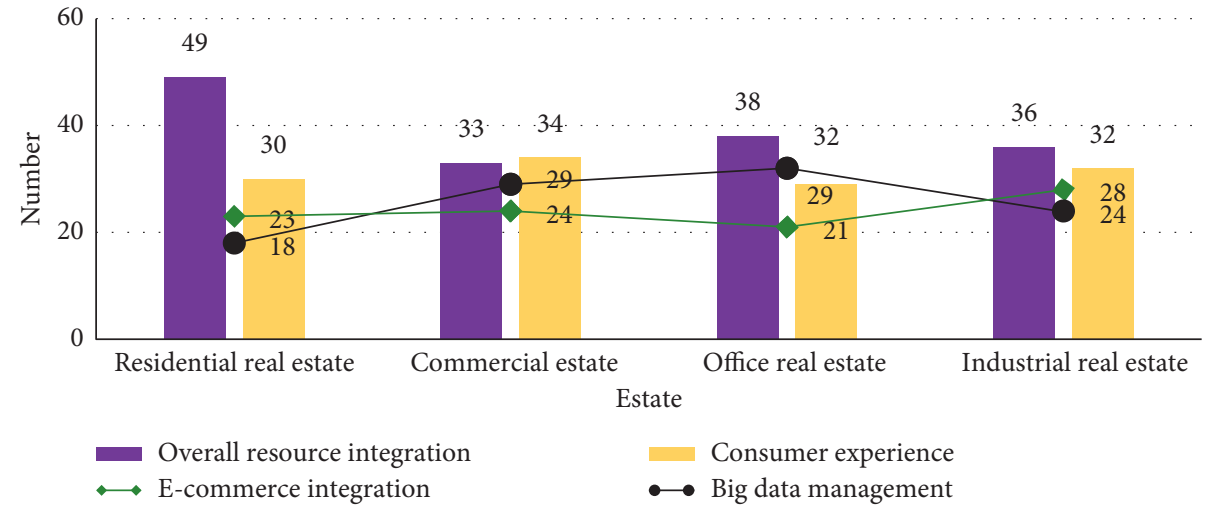

FIGURE 3: Survey results on the real estate development strategy.

TABLE 3: Survey results of consumer purchase intentions.

\begin{tabular}{lccc}
\hline Project & Consumer & Real estate developer & Real estate sales staff \\
\hline Personal characteristics & 28 & 27 & 24 \\
Internal demand motivation & 34 & 35 & 39 \\
Property characteristics & 30 & 35 & 36 \\
Social environment & 25 & 26 & 21 \\
\hline
\end{tabular}

demand motives, real estate characteristics, and social environment. Part of the questionnaire survey results is as follows.

\section{Analysis and Discussion}

4.1. Analysis of the Real Estate Development Strategy. This questionnaire survey launched a survey on real estate development strategies, including residential real estate, commercial real estate, office real estate, industrial real estate, agricultural real estate, and other uses of real estate, with regard to resource integration, consumer experience, e-commerce integration, big data management, etc. The survey results are shown in Figure 3.

As can be seen from Figure 3, of the 120 respondents, 49 people think that the overall resource integration strategy in residential real estate is the first priority, followed by consumer experience, while in office real estate, 38 people think the overall resource integration strategy is the first priority. It is a big data management strategy. It can be seen that most of the interviewees believe that the resource integration strategy occupies an important position in the real estate development strategy, and the big data management strategy also exerts its advantages.

4.2. Analysis of Consumers' Purchase Intention. This questionnaire survey will investigate and analyze consumers' purchase intentions in terms of personal characteristics, internal demand motives, real estate characteristics, and social environment. The survey results are shown in Table 3.

It can be seen from Table 3 that, among the 120 interviewees, including consumers, real estate developers, and real estate sales staff, 34,35 , and 39 , respectively, believe that internal demand motivation is the most important, followed by real estate characteristics. It can be seen that real estate development must fully consider the actual needs of consumers and improve the development process to highlight the characteristics of real estate.

\section{Conclusion}

Starting from 2020, the Chinese government has stepped up its macrocontrol of the real estate market. Some real estate companies that rely on disorderly expansion have fallen into a quagmire, and the development of real estate companies has entered a state of stagnation. The development of this research provides a new idea for the development of the real estate market so that it can better grasp the actual market demand with the help of information technology, so as to formulate a more scientific development strategy. With the application of artificial intelligence in various fields, it has had a huge impact on various industries, especially the real estate industry. At present, China is in the era of big data, and the opportunities and challenges of real estate development coexist. Therefore, it is necessary to combine the 
support of artificial intelligence and big data industrial policies to break through the bottleneck of real estate development. Therefore, this article combines artificial intelligence and big data industrial policies to carry out research on real estate development strategies, which has important practical significance and research value. Research shows that the resource integration strategy plays an important role in the real estate development strategy, and the big data management strategy also exerts its advantages. At the same time, real estate development should fully consider the actual needs of consumers and improve the development process to highlight the characteristics of real estate.

\section{Data Availability}

The datasets used and/or analyzed during the current study are available upon reasonable request to the author.

\section{Conflicts of Interest}

The author declares no conflicts of interest.

\section{References}

[1] Y. Shi, "The countermeasures of management accounting for real estate enterprises under the background of big data," Shangxun, vol. 198, no. 8, pp. 55-56, 2020.

[2] W. Luo, "Strategic research on the perfect combination of artificial intelligence and big data," Housing and Real Estate, vol. 565 , no. 6 , p. $269,2020$.

[3] X. Jin and X. Li, "Development and strategic planning of commercial real estate in the era of Internet consumption," Business and Economic Research, vol. 22, no. 20, pp. 125-127, 2016.

[4] D. Xie, "Business strategy of real estate development enterprises under the new economic situation," China International Finance and Economics (Chinese and English), vol. 31, no. 17, pp. 151-152, 2017.

[5] K. Fai, H. Lo, and Y. Huai, "Robust public-private partnerships for joint railway and property development," Frontiers of Engineering Management, vol. 4, no. 4, pp. 437-450, 2017.

[6] L. Ren, Q. Guo, and H. Wang, "Visual analysis of artificial intelligence literature big data based on CiteSpace," Computer Systems \& Applications, vol. 27, no. 6, pp. 20-28, 2018.

[7] X. Su and Y. Dai, "Practice of innovative management accounting talent training model under artificial intelligence and big data environment," The Journal, vol. 45, pp. 116-118, 2021.

[8] G. Chen, L. I. Jing, and H. Chen, "Research progress of artificial intelligence technology in agriculture in the era of big data," Journal of Jilin Agricultural University, vol. 40, no. 4, pp. 502-510, 2018.

[9] Y. Zou, "Big data and artificial intelligence: a new vision for the inference of post-mortem interval[J]," Journal of Forensic Medicine, vol. 36, no. 1, pp. 86-90, 2020

[10] J. Wang, "New financial thinking under the background of artificial intelligence and big data era," The Journal, vol. 17, pp. 195-196, 2021.

[11] S. Huang, L. Chen, and Z. Yin, "Research on systematic identification of strategic risks of real estate development enterprises," The Journal, vol. 25, pp. 90-91, 2021.

[12] K. Zhou, "Risk management of real estate development," Economic Journal, vol. 37, no. 2, pp. 341-342, 2016.
[13] J. Lu, "The interactive relationship between Chinas real estate development investment and GDP," Real Estate Guide, vol. 28, no. 24, p. 252, 2016.

[14] W. Cui, "Research on engineering management of real estate development and operation," Urban Construction Theory Research (Electronic Edition), vol. 46, no. 8, p. 2071, 2016.

[15] L. Wang, "Cost optimization control of real estate development projects," Commodity and Quality, vol. 33, no. 46, pp. 49-50, 2016.

[16] S. Wang, "Cost control of real estate development projects," Engineering Technology: Digest Edition, vol. 16, no. 3, Article ID 00173, 2016.

[17] S. Guo, "Countermeasures for real estate development enterprises to strengthen cost management," Engineering Technology, vol. 27, no. 5, Article ID 00194, 2016.

[18] L. Wang, "Factors affecting real estate economic development and solutions," Real Estate, vol. 18, no. 7, pp. 0039-0040, 2021.

[19] Z. Li, "Double carbon" strategy redefines the real estate development model," China Real Estate Finance, vol. 29, no. 7, p. $1,2021$.

[20] S. Lin, "Discuss how the real estate market can promote the development of real estate economy," Modern Enterprise, vol. 11 , no. 10 , p. 2, 2021.

[21] A. Zhang, "Analysis on the influence and development of real estate economy in the new era," Market Weekly. Theory Edition, vol. 21, no. 4, p. 2, 2021.

[22] Ye Fan, "Application of target cost method in cost management of real estate development projects," Low Carbon Real Estate, vol. 32, no. 19, pp. 189-190, 2016.

[23] Q. Zhang, "Engineering cost control of real estate development enterprises," Citation version: Engineering Technology, vol. 43 , no. 5 , p. 33, 2016.

[24] W. Wang and Z. Lu, "How to prevent "grey rhinoceros" - a mirror of real estate development from the United States, Japan, and Germany and China's policy recommendations for preventing systemic risks," China Economic Report, vol. 34, no. 2, p. 11, 2021.

[25] X. Cai and N. Lin, "Research on the coordinated development path of new urbanization and real estate industry in Fujian Province," The Journal, vol. 15, pp. 147-152, 2016. 